\title{
The Study of a New Method to Determine Copper lon by Square-Wave Voltammetry-Extraction lodometry at the Liquid/Liquid Interfaces
}

\author{
Changyan Shi, ${ }^{1}$ Shaoai Xie, ${ }^{2}$ and Jinping Jia ${ }^{1}$ \\ ${ }^{1}$ School of Environmental Science and Engineering, Shanghai Jiao Tong University, Shanghai 200240, China \\ ${ }^{2}$ School of Chemistry and Chemical Technology, Shanghai Jiao Tong University, Shanghai 200240, China
}

Correspondence should be addressed to Jinping Jia, cdsqbyl2006@126.com

Received 5 July 2008; Accepted 27 August 2008

Recommended by Peter Stockwell

A new method of indirect determination of $\mathrm{Cu}^{2+}$ was developed based on square-wave voltammetry by the oxidation of iodide in organic solvent at the liquid/liquid $(\mathrm{L} / \mathrm{L})$ interface. The limit of detection for the determination of $\mathrm{Cu}^{2+}$ in this method was found to be $5 \times 10^{-4} \mathrm{~mol} / \mathrm{L}$, and the concentration ranged up to $1 \times 10^{-2} \mathrm{~mol} / \mathrm{L}$ gave a linear limiting current versus concentration response. For the same simulated wastewater, this method showed high accuracy compared with the result tested by sodium diethyldithiocarbamate extraction spectrophotometry. This approach could be applied to the indirect determination of the oxidative heavy metals in the industrial wastewater.

Copyright (C) 2008 Changyan Shi et al. This is an open access article distributed under the Creative Commons Attribution License, which permits unrestricted use, distribution, and reproduction in any medium, provided the original work is properly cited.

\section{INTRODUCTION}

Heavy metals such as cadmium, lead, zinc, nickel, copper, and chromium (VI) or their compounds have been used extensively by various metal finishing, mining, and chemical industries. This has led to a sharp increasing in the contamination of water. Due to their toxicity, the presence of these metals in excessive quantities will interfere with many beneficial uses of the water. For these reasons, it is necessary to explore a simple, sensitive and accurate detection method.

Many analytical methods have been developed for determination of heavy metals in water, such as colorimetric analysis [1], UV-VIS spectroscopy [2-4], and either flame or graphite furnace atomic absorption spectrometry (AAS) [5-8]. In addition to these techniques, methods for multielemental determination have been developed, such as ion chromatography (IC) [9-11] and inductively coupled plasma combined with either atomic emission spectrometry (ICPAES) [12] or mass spectrometry (ICP-MS) [13, 14].

Although these methodologies are rapid and sensitive for the determination of trace amounts of metals, they require complicated instrumentation with high capital and operational costs. Furthermore, these methods are not easily implemented into fully portable analytical tools for screening, detecting, identifying, and quantifying metal ions.

Different from these methods, electrochemical detection (ED), such as polarography, offers high sensitivity and selectivity for metals that are readily oxidized or reduced with simple instrumentation and low capital and operational costs. Therefore, it is suitable for online monitoring. Now, the application of polarography has been limited for the toxicity of mercury.

Electrochemistry at liquid/liquid $(\mathrm{L} / \mathrm{L})$ interfaces is mostly studying charge (ion and charge) transfer across an interface between two immiscible electrolyte solutions and the associated chemical reactions. Based on the special property of the interface between two immiscible electrolyte solutions (ITIESs), using appropriate organic solvents with low toxicity to substitute toxic mercury is a new area for monitoring heavy metals.

Square-wave voltammetry is a large-amplitude differential technique in which a waveform composed of a symmetrical square wave, superimposed on a base staircase potential, is applied to the working electrode. Now, squarewave voltammetry has been applied in the field of ITIES. Mirceski and Scholz [15] studied the electrochemistry of 


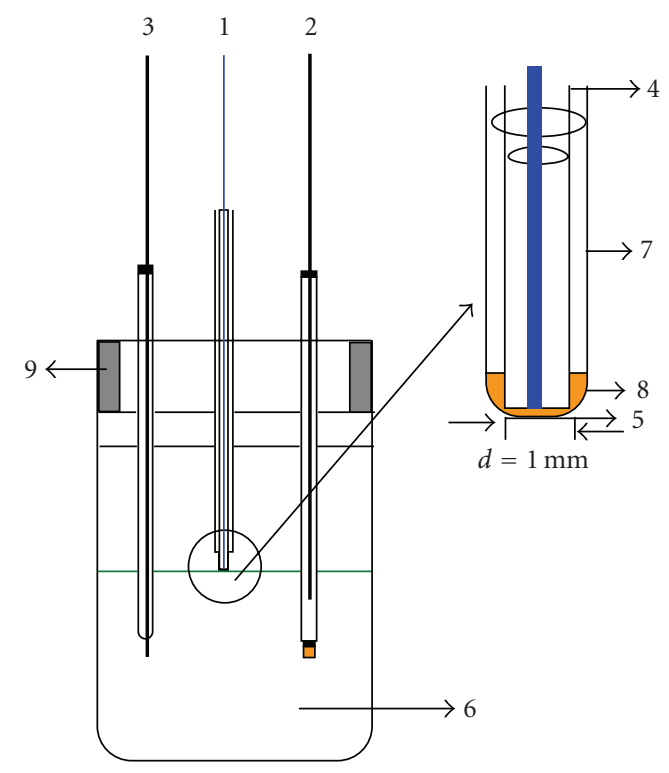

FIgURE 1: Schematic diagrams of the electrochemical cell (1) WE (Pt wire), (2) RE(SCE), (3) $\mathrm{CE}(\mathrm{Pt})$, (4) $0.1 \mathrm{~mm}$ Pt wire, (5) L/L interface, (6) aqueous solution, (7) pipette, (8) organic phase, and (9) Lid.



FIGURE 2: Relationship between volume ratio and the peak current.

iodine/iodide redox couple at the three-phase arrangement organic liquid (aqueous solution) graphite electrode of a reversible electrochemical process using square-wave voltammetry as the electro chemical method.

In this paper, a simple method of monitoring copper ions indirectly was designed by investigating the electrochemical reactions of iodine at the $\mathrm{L} / \mathrm{L}$ interface with square-wave voltammetry. Different from the study of Mirceski and Scholz, a new composite electrode was chosen as the working electrode, which was prepared by inserting a Pt wire electrode into a micropipette. An organic solvent containing extracted iodine was injected into the pipette, thus the liquid/liquid interface was supported by setting the pipette just on the surface of aqueous solution below. Xie et al. [16] have studied the electrochemical behavior of iodine using such kind of electrode, and analyzed it by cyclic voltammetry. This paper improved their study from two aspects. First, by using square-wave voltammetry to substitute cyclic voltammetry, the analysis time was drastically reduced and its keen-edged peak shape made the curve more easily to scale the peak current and realize quantitative detection compared with cyclic voltammetry. Second, in the process of extraction, the volume of organic solvent was smaller than the volume of the stock aqueous solution which contained triiodide, rather than equal. As the concentration of extracted iodine in the organic solvent showed to be dramatically high in the smaller volume of organic solvent under the premise that the total amount of extracted iodine did not change, the peak current could be higher.

\section{EXPERIMENTAL PART}

\subsection{Instruments and chemicals}

All the salts used as the supporting electrolytes were used as purchased and all the chemicals used here were of analytical grade. The aqueous solutions were prepared in deionized water. Organic solvents were saturated with deionized water prior to experiments. A stock aqueous solution of triiodide was determined by iodometry. Some solutions of iodine in organic solvent (methyl isobutyl ketone (MIBK)) were prepared by the extraction of iodine from a triiodide stock solution in water saturated MIBK.

All electrochemical experiments were performed at room temperature $(25 \pm 1)^{\circ} \mathrm{C}$ with an electrochemical analyzer (CHI832b, Chenhua, Shanghai, China); UV-VIS spectra were measured with a UV-VIS (UNICO UV-2102, UNICO (Shanghai) Instrument Co. Ltd, Shanghai, China).

\subsection{Experimental procedures}

A conventional three-electrode cell was used, in this work by using saturated calomel electrode (SCE) as the reference electrode ( $E=0.241 \mathrm{~V}$ versus standard hydrogen electrode) and a platinum electrode as the auxiliary electrode. The working electrode was a platinum wire $(d=0.1 \mathrm{~mm})$ sealed in a classical capillary $(d=1.0 \mathrm{~mm})$. Prior to all experiments, the platinum wire was immerged into $1 \mathrm{~mol} / \mathrm{L} \mathrm{H}_{2} \mathrm{SO}_{4}$ to be activated during cyclic voltammetric experiments. After activation, it was polished with sheepskin, cleaned successively with alcohol and acetone, and then dried with a hair drier. After that, $20 \sim 40 \mu \mathrm{L}$ of MIBK containing iodine was injected into a pipette using a microsyringe, and the platinum wire electrode was immersed into it. Then the combined electrode was immediately set just on the surface of the aqueous solution. The schematic diagram of the experimental assembly is shown in Figure 1. The liquid/liquid interface between aqueous phase and organic phase was supported as shown in part 5 of the Figure 1 (the cell employed and an interfacial area of $0.8 \mathrm{~mm}^{2}$ ). During square-wave voltammetry experiments, neither a significant distortion nor a change of the color of the organic phase 


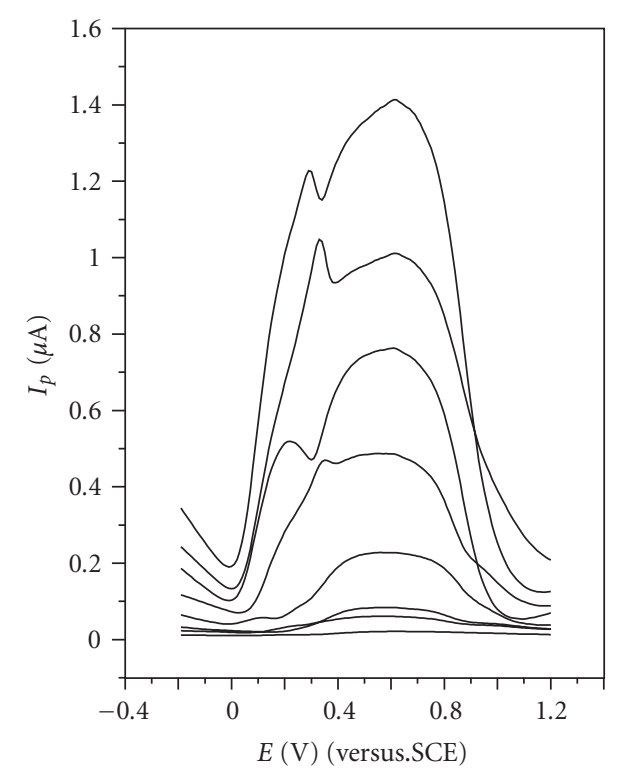

(a)

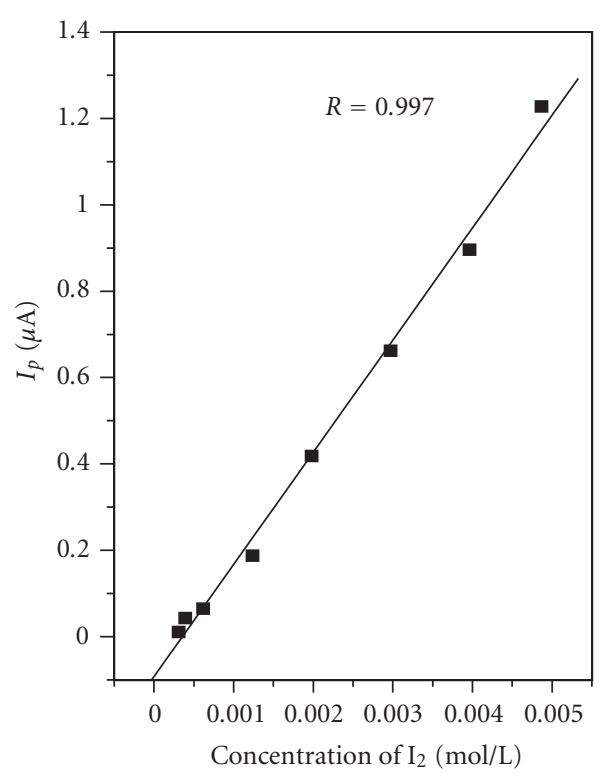

(b)

FIGURE 3: (a) Square-wave voltammograms of various iodine concentrations in MIBK: amplitude $0.15 \mathrm{~V}$ and frequency $10 \mathrm{~Hz}$, (b) the peak current versus concentration of iodine in solution: the iodine concentrations (in mol/L): $0.0049,0.0040,0.0030,0.0020,0.0012,0.00062$, $0.00040,0.00031$.

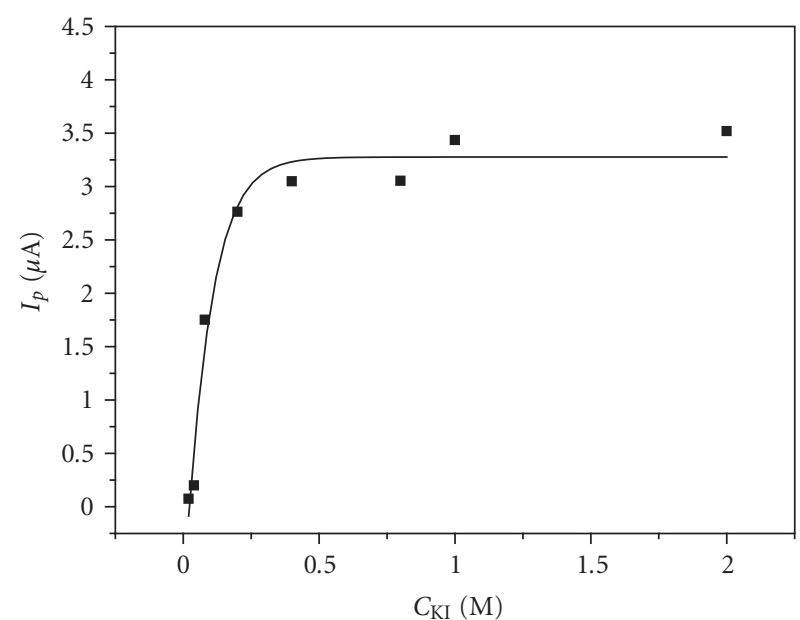

FIGURE 4: Dependence of peak current on the concentration of KI.

had been observed. The interfacial area influences only the measured currents, where both the position of the response (peak potential) and the shapes were not affected.

\section{RESULTS AND DISCUSSION}

\subsection{The effect of extractive volume ratio on peak current}

The effect of volume ratio between organic solvent (MIBK) and triiodide stock solution on peak current is shown in Figure 2. Different volumes of MIBK, that is, $10 \mathrm{~mL}, 8 \mathrm{~mL}$, $6 \mathrm{~mL}, 4 \mathrm{~mL}, 2 \mathrm{~mL}$ were used to extract iodine from $10 \mathrm{~mL}$ aqueous phase. As shown in Figure 2, the peak currents varied when using different volumes of extractant and appeared significantly high when volume ratio was 0.2 . This is in agreement with the principle that the concentration of iodine in MIBK increases along with the decrease of extractant volume under the premise that the total amount of extracted iodine did not change.

\subsection{Quantitative determination of iodine}

The triiodide stock aqueous solution was prepared with $\mathrm{I}_{2}$ and KI, and after investigation the authors came to the conclusion that the peak current does not change when using different mole ratio of $\mathrm{I}_{2}$ and KI. So a solution in which the mole ratio between $\mathrm{I}_{2}$ and $\mathrm{KI}$ was 1:8 was chosen and diluted into different concentrations.

The square-wave voltammograms (SWVs) of various concentrations of iodine in the triiodide stock aqueous solution chosen above are shown in Figure 3(a). The mechanism of iodine oxidation at the electrode surface can be explained as in literature 16. The peak current was directly proportional to $\mathrm{I}_{2}$ concentration as shown in Figure 3(b). The proportionality coefficient was 0.9970 . So it is reasonable to suggest that the indirectly quantitative determination of $\mathrm{Cu}^{2+}$ is feasible.

\subsection{Quantitative determination of $\mathrm{Cu}^{2+}$}

As it is well known, an oxidizing analyte is added to excess $\mathrm{I}^{-}$to produce iodine and then the iodine is titrated with standard thiosulfate solution [17]. In this method, an indicator and standard solution are prepared. Here, the method of measuring the content of iodine in solution was 


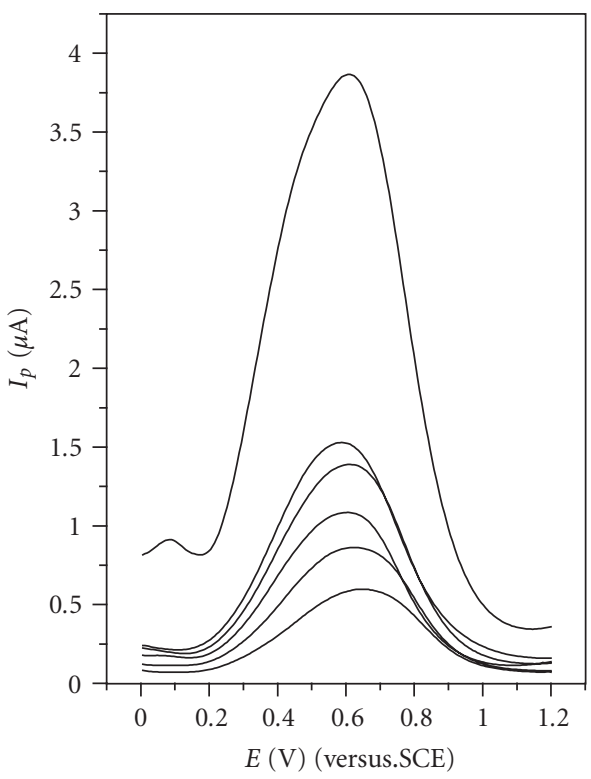

(a)

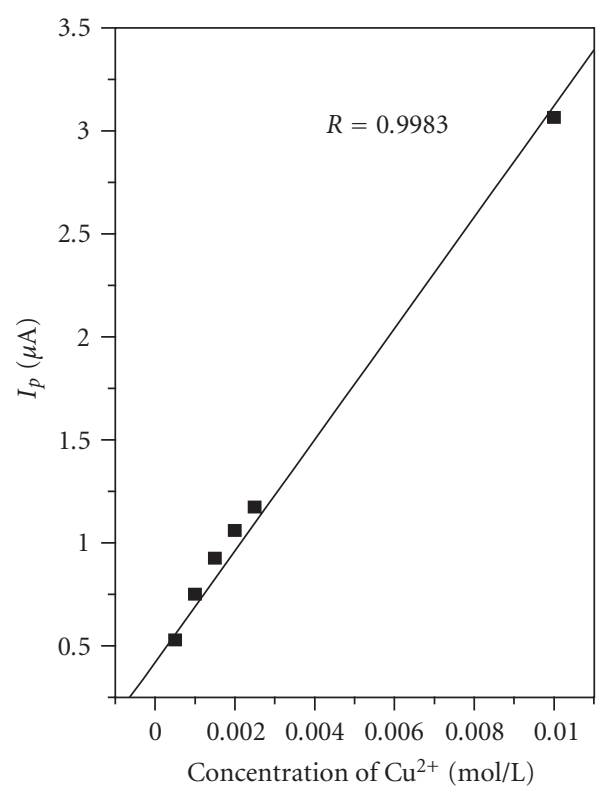

(b)

FIGURE 5: (a) Square-wave voltammograms of various iodine concentrations in MIBK: amplitude $0.15 \mathrm{~V}$ and frequency $10 \mathrm{~Hz}$, (b) the peak current versus concentration of copper ion in solution; the $\mathrm{Cu}^{2+}$ concentration (in mol/L): 0.01, 0.0025, 0.002, 0.0015, 0.001, 0.0005.

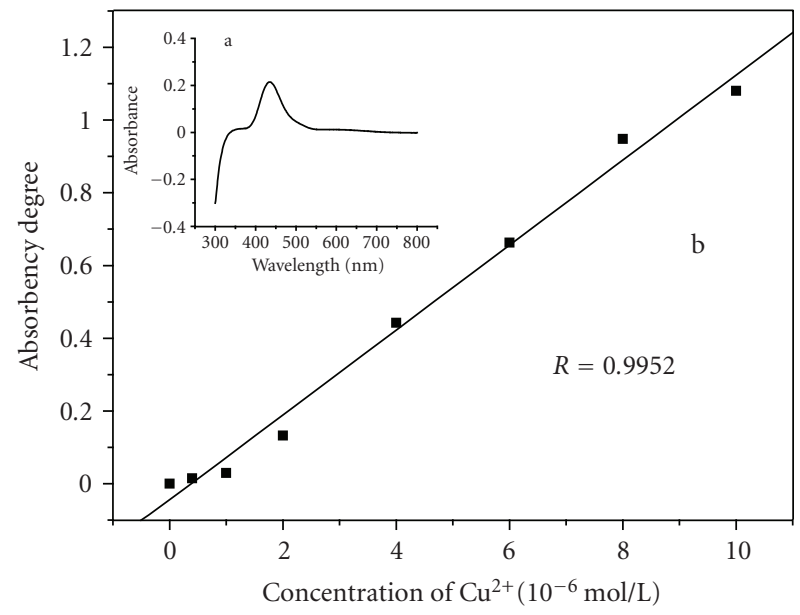

FIgURE 6: The absorbency degree versus concentration of $\mathrm{Cu}^{2+}$ in solution.

improved. Iodine was prepared according to the chemical reactions as follows:

$$
2 \mathrm{Cu}^{2+}+5 \mathrm{I}^{-} \Longleftrightarrow 2 \mathrm{CuI}(\mathrm{s})+\mathrm{I}_{3}^{-} .
$$

Then various concentrations of iodine were extracted into MIBK. Solvent extraction is a well established separation technique based on the principle that a solute can distribute itself in a certain ratio between two immiscible solvents, one of which is usually water and the other organic solvent. This method is widely used because of its simplicity, speed, and applicability to low analyte concentrations.

The square-wave voltammograms of the iodine prepared by reaction of $0.02 \mathrm{~mol} / \mathrm{L} \mathrm{Cu}^{2+}$ and various concentrations of $\mathrm{I}^{-}$in a neutral electrolyte were obtained and the relationship between the concentrations of $\mathrm{I}^{-}$and the peak current is shown in Figure 4. The peak current increased along with the increasing of $\mathrm{I}^{-}$'s amount when the concentrations of $\mathrm{I}^{-}$were less than $0.8 \mathrm{~mol} / \mathrm{L}$ and stayed almost invariable when the concentrations of $\mathrm{I}^{-}$were higher than $0.8 \mathrm{~mol} / \mathrm{L}$. Then the conclusion was made that the peak currents are invariable when the amount of $\mathrm{I}^{-}$used is excess enough. So this study chose $1 \mathrm{~mol} / \mathrm{L} \mathrm{KI}$ as a reducer to produce iodine with different concentrations of $\mathrm{Cu}^{2+}$.

The square-wave voltammograms of the iodine prepared by the reaction of various concentrations of $\mathrm{Cu}^{2+}$ and $1 \mathrm{~mol} / \mathrm{L} \mathrm{I}^{-}$in a neutral electrolyte are shown in Figure 5(a). The peak current was directly proportional to $\mathrm{Cu}^{2+}$ concentration as shown in Figure 5(b). The proportionality coefficient was 0.9983 . The limit of detection for the determination of $\mathrm{Cu}^{2+}$ indirectly was found to be $5 \times 10^{-4} \mathrm{~mol} / \mathrm{L}$, and the concentration ranged up to $1 \times 10^{-2} \mathrm{~mol} / \mathrm{L}$ gave a linear limiting current versus concentration response.

\subsection{Detection for actual samples}

A simulated wastewater containing $\mathrm{Cu}^{2+}$ was prepared and the peak current was determined through the same procedure as mentioned before. Then the concentration of $\mathrm{Cu}^{2+}$ in the sample was determined by the regression equation of Figure $6(\mathrm{~b})\left(Y=4.952 \times 10^{-7}+2.587 \times 10^{-4} X\right)$ based on the peak current $\left(1.731 \times 10^{-6} \mathrm{~A}\right)$. The result is $4.777 \times 10^{-3} \mathrm{~mol} / \mathrm{L}$.

Besides the method studied in this paper, another classical method, spectrophotometry was also used as comparative study to determine the same sample. The absorbency degree of various concentrations of $\mathrm{Cu}^{2+}$ colored by sodium diethyldithiocarbamate (DDTC) was detected 
by the UV-VIS at the wavelength of $440 \mathrm{~nm}$ and directly proportional to $\mathrm{Cu}^{2+}$ concentration as shown in Figure 6. The proportionality coefficient was 0.9952. After diluting 1000 times, the concentration of $\mathrm{Cu}^{2+}$ in the sample was determined by the regression equation of Figure 6(b) ( $Y=$ $-0.045+116848.0315 X)$ based on the absorbency degree (0.446). So the $\mathrm{Cu}^{2+}$ concentration in this sample is 4.202 $\times 10^{-3} \mathrm{~mol} / \mathrm{L}$.

The two results of the same sample showed that the method studied in this paper gives good result with high accuracy in agreement with the result of spectrophotometry.

The interference experiment also showed that the peak current would not be interfered when the concentration of coexisted reductive metals ( such as $\mathrm{Zn}^{2+}, \mathrm{Ni}^{2+}$ ) was ten times as the target metal. When existing two or more than two kinds of oxidative metals, the method could determine the total amount.

\section{CONCLUSIONS}

A new method of indirect determination of $\mathrm{Cu}^{2+}$ has been characterized by the oxidation of iodide in organic solvent at the $\mathrm{L} / \mathrm{L}$ interface, in which the ion transfer from aqueous solution to organic phase proceeds. Considering the strong reductive properties of iodide in aqueous solution, iodine can be obtained by chemical reactions between excess iodide and heavy metal ions (e.g., $\mathrm{Cu}^{2+}$ ) in solution, then the content of heavy metal ions can be determined indirectly using the present method. The limit of detection for the determination of $\mathrm{Cu}^{2+}$ indirectly was found to be $5 \times 10^{-4} \mathrm{~mol} / \mathrm{L}$, and the concentration ranged up to $1 \times 10^{-2} \mathrm{~mol} / \mathrm{L}$ gave a linear limiting current versus concentration response. Compared the result with sodium diethyldithiocarbamate extraction spectrophotometry, this method shows high accuracy. The advantage of this method is that it can be operated much more easier than sodium diethyldithiocarbamate extraction spectrophotometry.

The limit of detection was not low enough because the peak position appeared at $0.8 \mathrm{~V}$, away from its normal position when the concentration of $\mathrm{Cu}^{2+}$ was lower than 5 $\times 10^{-4} \mathrm{~mol} / \mathrm{L}$. The reason for the potential shift is yet to be studied.

This approach could be applied to the indirect determination of the oxidative heavy metals, such as $\mathrm{Cu}^{2+}, \mathrm{Cr}$ (VI) in the industrial wastewater.

\section{ACKNOWLEDGMENT}

The authors acknowledge the financial support provided by "863" project (Grant no. 2006AA06Z405) from the Ministry of Science and Technology of the People's Republic of China.

\section{REFERENCES}

[1] A. Abbaspour, M. A. Mehrgardi, A. Noori, M. A. Kamyabi, A. Khalafi-Nezhad, and M. N. S. Rad, "Speciation of iron(II), iron(III) and full-range $\mathrm{pH}$ monitoring using paptode: a simple colorimetric method as an appropriate alternative for optodes," Sensors and Actuators B, vol. 113, no. 2, pp. 857-865, 2006.
[2] J.-P. Cornard, A. Caudron, and J.-C. Merlin, "UV-visible and synchronous fluorescence spectroscopic investigations of the complexation of $\mathrm{Al}(\mathrm{III})$ with caffeic acid, in aqueous low acidic medium," Polyhedron, vol. 25, no. 11, pp. 2215-2222, 2006.

[3] N. Tounsi, L. Dupont, A. Mohamadou, et al., "Thermodynamic and spectroscopic studies of copper (II) complexes with three bis(amide) ligands derived from L-tartaric acid," Journal of Inorganic Biochemistry, vol. 99, no. 12, pp. 2423-2435, 2005.

[4] A. Torreggiani, M. Tamba, A. Trinchero, and S. Bonora, "Copper(II)-Quercetin complexes in aqueous solutions: spectroscopic and kinetic properties," Journal of Molecular Structure, vol. 744-747, pp. 759-766, 2005.

[5] N. Panichev, K. Mandiwana, M. Kataeva, and S. Siebert, "Determination of $\mathrm{Cr}(\mathrm{VI})$ in plants by electrothermal atomic absorption spectrometry after leaching with sodium carbonate," Spectrochimica Acta Part B, vol. 60, no. 5, pp. 699-703, 2005.

[6] J. Falandysz, A. Jędrusiak, K. Lipka, et al., "Mercury in wild mushrooms and underlying soil substrate from Koszalin, North-central Poland," Chemosphere, vol. 54, no. 4, pp. 461466, 2004.

[7] C. J. de Castro Maciel, G. M. Miranda, D. P. de Oliveira, et al., "Determination of cadmium in human urine by electrothermal atomic absorption spectrometry," Analytica Chimica Acta, vol. 491, no. 2, pp. 231-237, 2003.

[8] M. V. Aguilar, C. J. Mateos, and M. C. Martínez Para, "Determination of chromium in cerebrospinal fluid using electrothermal atomisation atomic absorption spectrometry," Journal of Trace Elements in Medicine and Biology, vol. 16, no. 4, pp. 221-225, 2002.

[9] W. Zeng, Y. Chen, H. Cui, F. Wu, Y. Zhu, and J. S. Fritz, "Singlecolumn method of ion chromatography for the determination of common cations and some transition metals," Journal of Chromatography A, vol. 1118, no. 1, pp. 68-72, 2006.

[10] M. J. Shaw and P. R. Haddad, "The determination of trace metal pollutants in environmental matrices using ion chromatography," Environment International, vol. 30, no. 3, pp. 403-431, 2004.

[11] C. Sarzanini and M. C. Bruzzoniti, "Metal species determination by ion chromatography," TrAC-Trends in Analytical Chemistry, vol. 20, no. 6-7, pp. 304-310, 2001.

[12] M. Türkmen and C. Ciminli, "Determination of metals in fish and mussel species by inductively coupled plasma-atomic emission spectrometry," Food Chemistry, vol. 103, no. 2, pp. 670-675, 2007.

[13] Y. Şahan, F. Basoglu, and S. Gücer, "ICP-MS analysis of a series of metals (namely: $\mathrm{Mg}, \mathrm{Cr}, \mathrm{Co}, \mathrm{Ni}, \mathrm{Fe}, \mathrm{Cu}, \mathrm{Zn}, \mathrm{Sn}, \mathrm{Cd}$ and $\mathrm{Pb}$ ) in black and green olive samples from Bursa, Turkey," Food Chemistry, vol. 105, no. 1, pp. 395-399, 2007.

[14] J.-P. Goullé, L. Mahieu, J. Castermant, et al., "Metal and metalloid multi-elementary ICP-MS validation in whole blood, plasma, urine and hair: reference values," Forensic Science International, vol. 153, no. 1, pp. 39-44, 2005.

[15] V. Mirceski and F. Scholz, "Reduction of iodine at the organic liquid vertical bar aqueous solution vertical bar graphite electrode three-phase arrangement," Journal of Electroanalytical Chemistry, vol. 522, no. 2, pp. 189-198, 2002.

[16] S. Xie, J. Jia, and H.-J. Chen, "Cyclic voltammetry of iodine at the organic liquid/ aqueous solution interface," Collection of Czechoslovak Chemical Communications, vol. 72, no. 7, pp. 917-926, 2007.

[17] D. C. Harris, Quantitative Chemical Analysis, W. H. Freeman, New York, NY, USA, 5th edition, 2001. 




International Journal of

Medicinal Chemistry

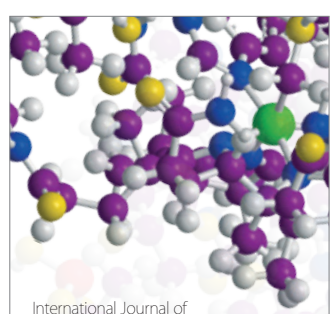

Carbohydrate Chemistry

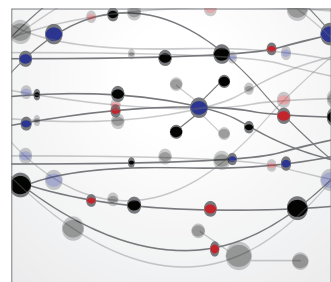

The Scientific World Journal
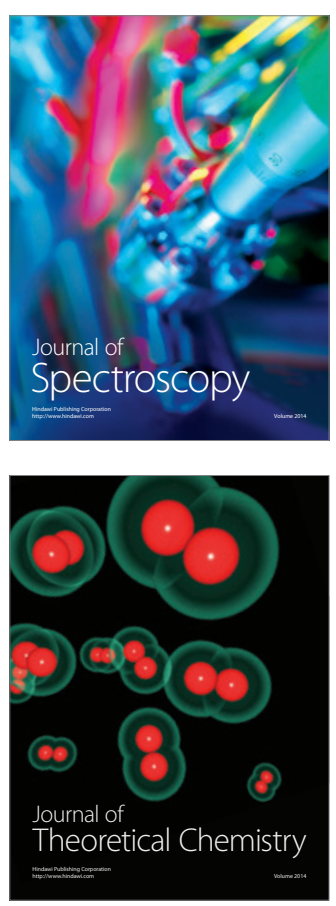
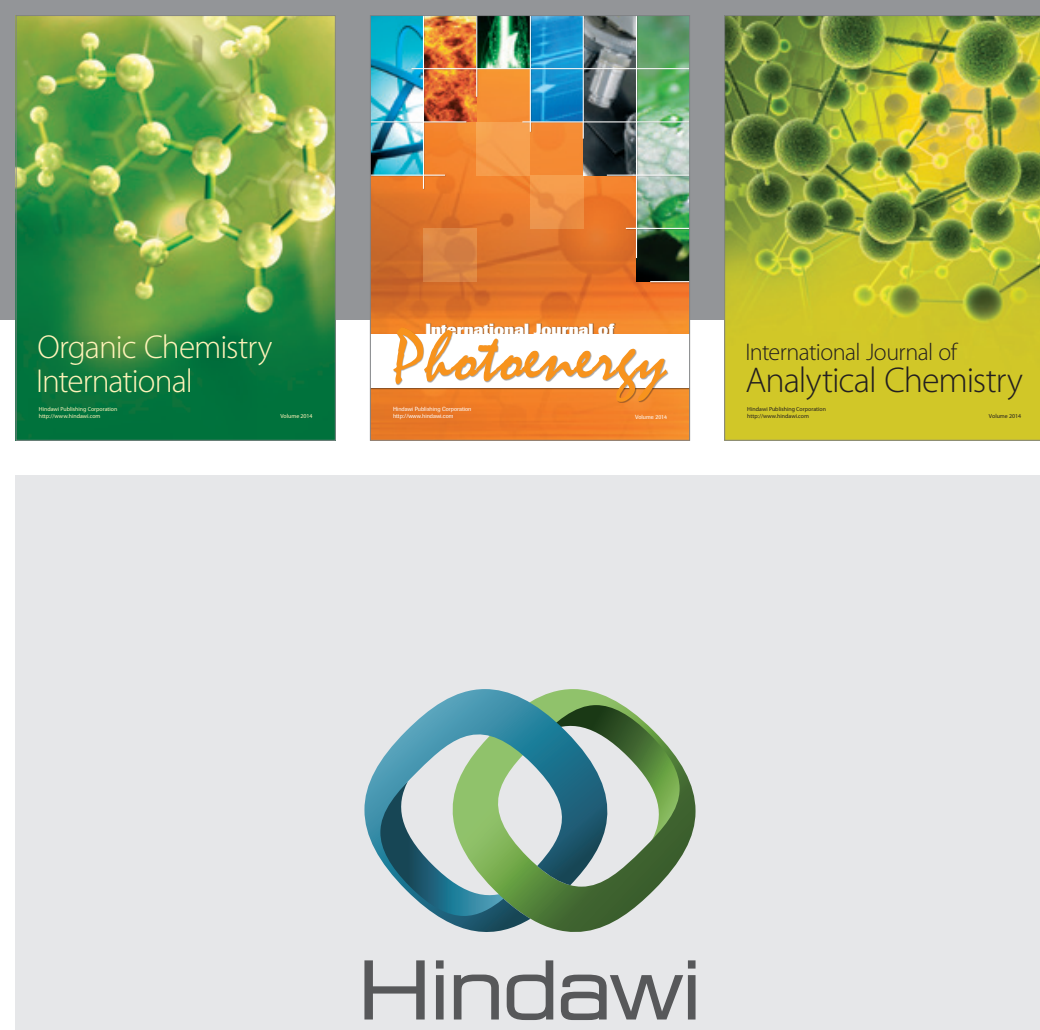

Submit your manuscripts at

http://www.hindawi.com
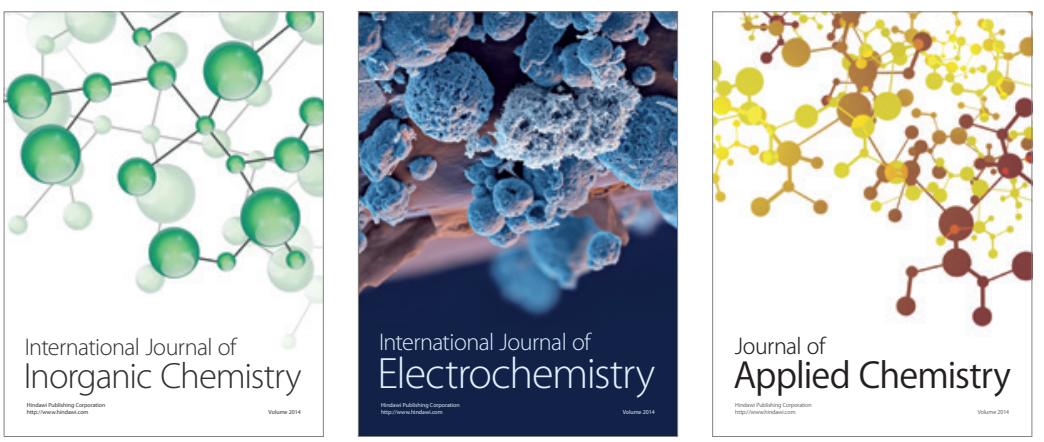

Journal of

Applied Chemistry
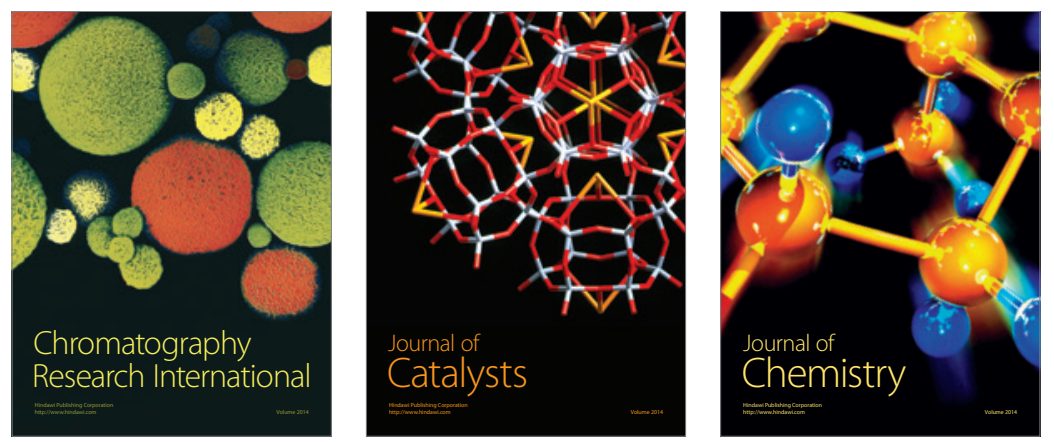
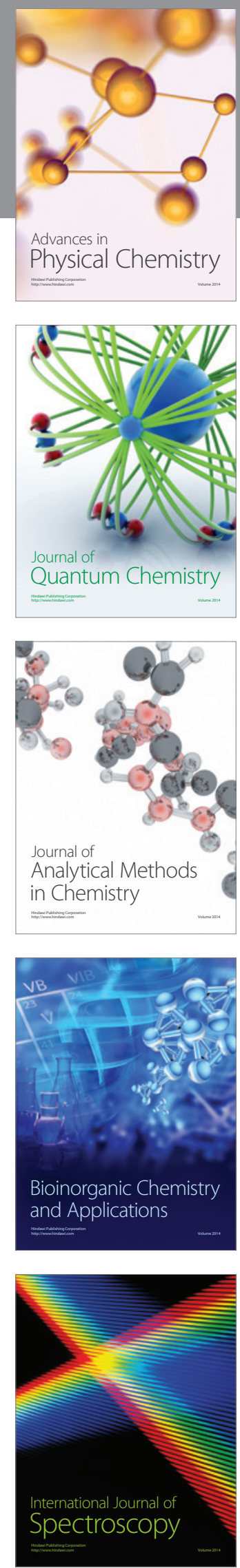